\title{
Causes of Intercultural Conflict and its Management Styles Among Students in Sunway University
}

\author{
Srikumar K. Ramayan ${ }^{1}$, Intan Abida bt. Abu Bakar², Vijaya Sooria Sangaran Kutty², \\ Kamdoum Keren Rosa ${ }^{4}$ \\ Department of Communication, School of Arts, Sunway University, MALAYSIA \\ Authors' email: 'srikumarr@sunway.edu.my; ${ }^{2}$ intana@sunway.edu.my; \\ 3vijayask@sunway.edu.my; ${ }^{4}$ kamdoum.r@imail.sunway.edu.my
}

Published: 28 September 2020

\begin{abstract}
The purpose of this study is to discover the causes of intercultural conflict and its management styles among Sunway University students. A total of six participants were selected from among different departments at Sunway university. A qualitative method was used to achieve the objectives of this research through in-depth interviews. the causes of intercultural conflict and its management styles were assessed based on intercultural conflict and intercultural conflict management style theory. The participants' feedback was transcribed and analyzed by using the deductive coding method which identified themes such as intercultural conflict, impact on intercultural conflict on relationships as well as intercultural conflict management styles that comprises of five categories, obliging, dominating, avoiding, compromising and integrating style. The results suggest, misunderstanding, as the main cause of intercultural conflict and it impacts people both positively and negatively depending on the situation. While suggesting avoiding style as the most used style of overcoming intercultural conflict among Sunway university students when it comes to gender, race, religion and cultural issues. The research findings will add to existing work on intercultural conflict and its management styles.
\end{abstract}

Keywords: Intercultural Conflict, Management Styles, Sunway University

eISSN: 2550-214X (C) 2020. The Authors. Published for Idealogy Journal by UiTM Press. This is an Open Access article distributed under the terms of the Creative Commons Attribution-NonCommercial-NoDerivatives License (http://creativecommons.org/licenses/by-nc-nd/4.0/), which permits non-commercial re-use, distribution, and reproduction in any medium, provided the original work is properly cited, and is not altered, transformed, or built upon in any way.

\section{INTRODUCTION}

Conflict is a difference of ideas or opinions. The opposition of one party to another usually fuels Conflicts, in an attempt to reach an objective different from that of the other party. ("What is Conflict?" 2018). The elements involved in the conflict have varied sets of principles and values, thus allowing such a conflict to arise. In a team consisting of people from different backgrounds with different skills, experience and worldview, there are bound to be conflict due to the way each one of them views the world. conflict happens at whatever point incongruent and unpleasant exercises happen (Deutsch, 2003). Conflict is an apparent of intrigue or a conviction that the gatherings' and individuals' present desires can't be accomplished all the while the way they need it to be. Roloff and Soule, (2002) call attention to that conflict is associated with meaning, meaning is associated with learning, and learning is established in culture.

Conflict is when two or more values, perspectives and opinions are contradictory in nature and have not been aligned or agreed about yet. (Shupe, 2007) Interpersonal relationships are a big part of daily life. It highlights the important people in of people's lives, regarding family, friends and even strangers, thus looking at conflicts in intercultural can help individuals analyze how it affects them and the relationships they have. It helps provide a framework of whether or not ethnocentrism in being practiced in the way they relate with the people around them. (Shupe, 2007)

Conflicts occur at most times and experienced by people from various backgrounds such as cultures, gender, religion and lifestyles. It can be identified with so many factors as racial segregation, contrasts in 
standards and social values, communication issues. Researchers have tended to the battles of international students from an assortment of viewpoints, counting social conflicts, segregation, money related troubles, pining to go home, dialect hindrances, legitimate status issues, what's more, psychological concerns (e.g., Ruble and Zhang, 2013; Wei, Tsai, Chao, Du, and Lin, 2012).

\subsection{Statement of Problem}

In today's reality, a lot of students are being sent all over the world to study and thus requiring them to understand and adjust to different lifestyles and cultures. Intercultural conflict as one of the divisions in the study of conflict is among the most overpowering stressors when living in an outside land. It can be challenging for both local and international students if not managed properly (Shupe, 2007). Studies have shown that These adjustment difficulties are attributable to the significant differences between cultural such as the values of collectivism and individualism (Lee, 2014), different communication and learning styles (Ruble \& Zhang. 2013), high levels of academic stress (Liao \& Wei, 2014), and lack of social support in the United States (Chavajay, 2013) This can be challenging for international students as most of them leave their families and loved ones to go to an unknown place and often find it hard adapt and integrate themselves into the new culture.

They experience all sorts of conflicts that often affect their academic performances as well as their social environment. Local students on the other hand also conflicts they are embracing people from different background and life experiences who doesn't necessarily share the same worldview as them. Previous studies have shown that international students are more likely to experience cultural adjustment difficulties and psychological distress than domestic students (Poyrazli, Kavanaugh, Baker, \& Al-Timimi, 2004). Disagreements often arise within local and international students due to their difference in opinions and misunderstanding, some like others have a hard time in dealing with these issues or finding a management style that can enable both parties reach an agreement due to cultural differences (Poyrazli, Kavanaugh, Baker, \& Al-Timimi, 2004).

\subsection{Objective of the Study}

The objectives of this research are:

1. To determine the causes of intercultural conflict among students in Sunway University.

2. To determine the intercultural conflict management styles used by the students to overcome their intercultural conflict.

\subsection{Research Questions}

1. What are the causes intercultural conflicts among youths in Sunway University?

2. What are the different conflict management styles used by students use to overcome intercultural conflict?

\subsection{Significance of Study}

The significant of this study is to provide a platform to Sunway University counsellors on the extent of student facing intercultural conflicts. It will help them identify them through different types of behaviours displayed by such students. This study would enable them to know how to take actions that could help in managing their problems. The study will also benefit future researchers who are interested in intercultural conflicts and management style. It will also benefit the students to be more aware of the different styles involved in conflict resolution and finding the one that suits them the most as well as the people around them. 


\section{LITERATURE REVIEW}

\subsection{Intercultural conflict}

Intercultural conflict is a perceived or real incompatibility of goals, values, expectations, processes, or outcomes between two or more interdependent individuals or groups. (Martins \& Nakayama, 2013). There isn't one shared reality between people, and this is the place where there are many wellsprings of conflict. (Lee, 2013) also described intercultural conflict as an anticipation that others will work from similar orientations as well as values that we hold, and when they don't, we conflict and clashes. For many international students' intercultural conflict can take place due to difference background and experiences. International student is a various gathering of sojourners from everywhere throughout the world, any number of social contrasts can bring about relational conflicts. Fellow international students, particularly those from similar foundations (Lee, 2006), can likewise be a noteworthy wellspring of social support in view of their normal encounters and shared understandings of the difficulties of living in an outside nation.

According to Hammer (2009, 2010, 2011), Building intercultural competence regarding conflicts involves increasing cultural self-awareness; deepening understanding of the experiences, values, perceptions, and behaviors of people from diverse cultural communities; and expanding the capability to shift cultural perspective and adapt behavior to bridge across cultural differences. Students are expected to adapt and get used to different settings, the best way conflicts are solved is thought to be culturally learned (Hammer, 2005). The Denial and Polarization mindsets are monoculture in their orientation and reflect the view that "one's own culture is central to reality" (Bennett, 1993, p.30). Researchers have highlighted individualism-collectivism culture as stressors of intercultural conflict.

Individualism collectivism is the major theoretical dimension of cultural variability used to explain cultural differences in interpersonal behavior across disciplines around the world (Chinese Culture Connection, 1987; Gudykunst \& TingToomey,1988; Hofstede, 1980; Hui \& Triandis, 1986; Triandis, 1988). Members of individualistic cultures are governed by the moral codes of an internalized, "freewheeling" self, and members of collectivistic cultures are influenced by the implicit moral standards of a connected "public" self. While members in both cultural systems have a need for face maintenance, the moral standards, and orientations that underlie face maintenance needs are relatively different. Face possesses a general structure that is cast in the evaluative net of the culture. By and large, individualistic societies, esteem singular objectives over gathering objectives, singular worries over gathering concerns, also, singular rights and needs over collective duties and commitments. Collectivistic societies, conversely, esteem gathering objectives over individual objective. One of the key conflicts that arise as a result of intercultural conflict is interpersonal conflict (Hammer, 2005).

\subsection{Interpersonal conflict}

"Interpersonal conflict happens everywhere and at any time and is inherent in all societies" (Bazazew, 2017). According to the article, interpersonal conflict, involves value and/or personality differences arising from disagreements between individuals. Interpersonal conflicts are an inevitable and often detrimental Consequence of social life (Webb, 2017). It further elaborated that female students were commonly engaged in gossip and insulting while male students commonly practiced insulting and physical challenge. It was also noted that male students frequently create conflicts due to sexual harassment of female students. Article 2 on the other hand refers to the lack of communication a basis to destructive conflicts (Otieno, 2015). Otieno in his research found out that when students don't have the appropriate channels to voice out complains and worries, it results in conflict.

Intercultural Conflict is inevitable. It is negative when it leads to violence, undermines the communication relationship between the parties involved in the conflict, stimulates people to become uncooperative, or prevents the parties from addressing real issues or problems. It includes any overt and 
verbalized arguments in differences of opinion over any issue that could lead to a fight between students to students and university leaders (Peter, 1996; Windle \& Warren, 1999).

According Yingshan (2016), conflict is considered as a series of disagreement and incapability by Individuals who are unable to fulfill each other expectations. Hence a more truthful and constructive manner of approach needs to be practiced in order for reconciliation to take place. According to a research done by Lee and Chen (2015), they found out that an international student develops more psychological stress due to conflict than a local student. The integration process for international students can cause conflict in the way they are perceived by others. Studies by Amaize and Onoyoume (2013) on Conflict resolution in Osun State in Nigeria reveal that when conflicts are not resolved, or resolution is delayed, properties, lives and academic hours of unimaginable quantity are lost. Delay in conflict resolution led to disruption of academic calendars leading to economic as well as psychological exhaustion. Since conflict is inevitable in the organization, its management determines whether it will generate positive or negative effect on the organizational performance. Marcus (2014, p. 513) states that: "The process of change is, at its core, one of conflict resolution. Therefore, one can think of change as an outcome of a constructive or destructive conflict resolution process, and the process of change as a series of conflict resolution activities that lead to some new (changed) end-state."

\subsection{Theoretical Framework}

\subsubsection{Intercultural conflict management styles}

CONCERN FOR SELF

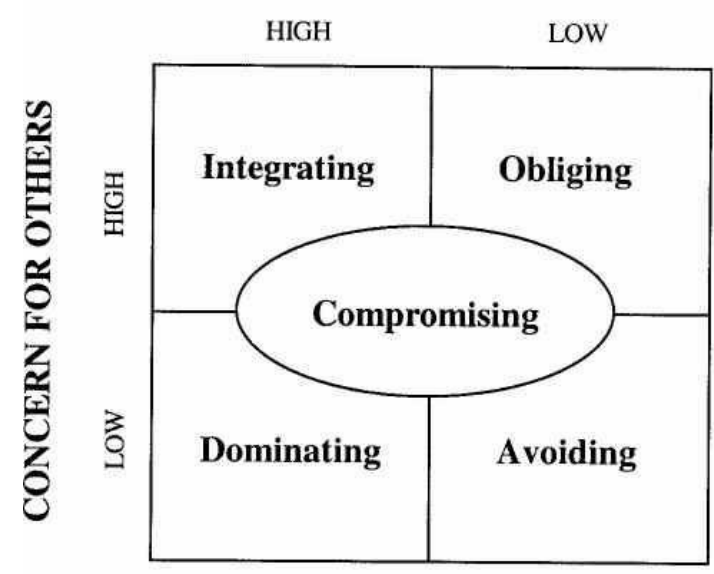

Figure 1: Conflict management styles

Gordon (2003) expressed that conflict management is the capacity to oversee conflict adequately. Cultural values such as individualism-collectivism and power distance shape people's initial expectations, attitudes, emotional reactions, face concerns and behaviors towards approaching or avoiding conflict (Toomey, Oetzel, 2001). As indicated by crafted by Leung $(1987,1988)$, Leung and Iwawaki (1988), Sternberg and Soriano (1984), and Walker (1990), people do display very predictable cross-situational styles of conflict management both inside and over the areas of interpersonal between authoritative, and international conflicts. Both social and identity inclinations have been revealed to be great indicators of reliable cross-situational styles of conflict management. In expansion, the idea of style consistency typifies both perceptual and behavioral events. Ting-Toomey (2006) additionally demonstrated that "contention style" is a socially grounded idea, which demonstrates that culture assumes a powerful part in a person's inclination of conflict styles. Intercultural Conflict management alludes to the modes utilized by either or the two gatherings to adapt to a contention. Conflict can't just be overseen, but instead requires techniques and individual skills that can keep it direct in associations (Cetin and Hacifazlioglu, 2004; Balay 2006). 
Various researchers have endeavored to think about individuals' behaviors in conflict and to recognize the best and most valuable ways to deal with conflicts. Rahim and Bonoma (1979) in view of past studies which take its starting point from Follett (1940), Blake \&Mouton (1964) and Thomas (1976) had proposed the separation of five intercultural conflict management styles into two measurements: worry for self and worry for others. The measurement of worry for self-clarifies the goal of how the individual endeavors to fulfill his own concerns which clarify the level of high or low worry for selfresults and then again, the measurement of worry for others clearly the individual needs to fulfill others concerns likewise comprises of high and low how much a man worries for alternate's results. Martin, J. N. \& Nakayama, T. K. (2013) proposed the four-dimensional way to manage intercultural conflict in context and the styles are as followed:

The discussion style - Verbally direct but emotionally restrained. Emphasizes verbally direct approach but keeps emotions in check. People are comfortable expressing disagreement.

The engagement style - Verbally direct and confrontational, views intense verbal \& nonverbal expression as showing sincerity individual shows a strong commitment to resolve conflict.

The accommodating style - Indirect and emotionally restrained. People make sure conflict does not get out of control Silence and avoidance are encouraged/adopted Preference for intermediaries, negotiations the style may end up sending ambiguous messages because of the unclarity in trying to resolve the conflict.

The dynamic style - Indirect communication but emotionally expressive. They are comfortable in showing their emotions, but they speak using metaphors, analogies to get points across.

The five-factor conflict management style displayed more clarity to catch the multifaceted intercultural conflict management style crosswise over cultures than other four-factor conflict instruments identified as discussion, dynamic. Engagement and accommodating. Looking at it from the five factor gives a detailed overview and explanation on how each individual use it for their advantage. It helps simplify meanings and give perspective where it's due.

Rahim, (2001) conceded conflict management styles, alludes to the distinctive styles of contention, looking at the ways in which people deal with their conflicts. These strategies are as per the following:

Integrating style - includes high worry for self and high worry for others. This includes transparency, exchange of data and examination of differences to achieve a powerful arrangement satisfactory to the both parties (Rahim, 1985 and Rahim, 1990).

Obliging style - includes moderate worry for self and high worry for others. This style is related with endeavoring to play down the distinctions and underlining shared traits to fulfill the worry of other party (Rahim, 1985 and Rahim 1990).

Dominating style - includes high worry for self and low worry for others. This style has been related to win-lose introduction or with compelling conduct to win one's position (Rahim, 1985 and Rahim 1990).

Avoiding style - includes low worry for self and low worry for others. It has been related with withdrawal, buck passing, or avoiding circumstances (Rahim, 1985 and Rahim 1990).

Compromising style - includes transitional in worry for self as well as other people. It includes giveand-take whereby the both parties surrender to make mutually acceptable decision (Rahim, 1985 and Rahim 1990). As researched by Ellen Toku on her conflict management thesis, she found out that the integrating style was the most preferred style among the responded of her interview followed by the compromising style as well as the obliging style. She highlighted that most participants chose this style as it allowed for the achievement of greater self-interest as well as the interest of others. 


\section{METHODOLOGY}

\subsection{Research Approach}

This research employed a qualitative approach to examine the causes of intercultural conflict and the different management styles used by Sunway University students to overcome conflict. This chapter outlines methodology that can be practical to achieve the research objectives and questions of this study.

The researcher conducted in-depth interview to have first-hand inputs and opportunities to analyze the data gathered from the chosen participants. The purpose of choosing qualitative approach is to gain insights, thoughts, motivations and opinions from participants regarding the causes of intercultural conflict and the preferred management styles. (Austin and Sutton, 2015)

\subsection{Sampling size}

The sampling size for this research were six students from Sunway University. Interviews were conducted on six students and including one for the pilot study. The six comprised of three local students, specifically Indian, Chinese, and Malay. The international student will vary from three different continents, Africa, Europe, and neighbouring Asian countries.

The researcher conducted purposive sampling due to the nature of the research objectives and was based on the researcher's judgement by choosing the member of the population to participate in the study (Dudovskiy, 2012) the study was strictly conducted on Sunway University students. A private room was booked prior to the interview and the duration of the interview ranged from 30 to 40 minutes. the in-depth interviews were audio and video recorded, transcribed and thematically coded using the deductive thematic analysis (Braun and Clarke, 2006). A free online transcribing through Google docs was utilized to record and transcribe the qualitative data collected from the in- depth interviews.

Before the researcher commenced the in-depth interviews, participants were given an informed consent form to read and sign. The researcher made it a priority to inform participants that their personal information will be kept anonymous, their participation in the interviews was entirely voluntary, and that they did not have to answer any questions that made them uncomfortable. All participants signed the consent form before taking part in the in-depth interview. Participants were briefed about intercultural conflict to give them a thorough understanding of the topic in case of any confusion.

Once the transcript was recorded and transcribed, the researcher searched for common themes, key words and direct questions to answers amongst the participants about their views and experiences on intercultural conflict and its management styles. Finally, the key words and answers were categorized into respective themes and analysed based on the findings from the participants.

\subsection{Data analysis}

The qualitative data for this research was analyzed by transcribing the in-depth interview responses from the participants. Upon transcribing the responses, open-coding analysis was applied to select answers to specific questions. The researched analyzed the transcribed data based on the themes which was developed from literature review and theoretical framework (refer to figure 1). Based on Corbin \& Strauss (1990) open coding is the interpretive process that breaks down data analytically/. It brings new insights by breaking through standard ways of thinking or interpreting the phenomena shown in the data. The use of open coding can make the questioning and constant comparisons break through subjectivity and bias

The two research questions consisted of nine questions that expanded more about the causes of intercultural conflict and intercultural conflict management style. five questions were directed at 
findings the causes of intercultural conflict, while the other four focused on intercultural conflict management styles. Once the interviews were done the researcher analyzed the themes, interpretations and ideas collected between the different interviews. The analysis was prepared by the researcher by describing the findings using the quotes within the interviews and tables to illustrate the answers given by different participants regarding the questions.

\section{FINDINGS AND DISCUSSION}

\subsection{Findings}

This chapter focuses on the results obtained after analyzing the data collected and discussion of the results, indicating whether the objectives were met or not. The interviews yielded some interesting findings. In analyzing the information each recorded interview was transcribed. In order to analyze the data, the transcribed data were categorized into broad themes in line with the research objectives and the interview guide. This allowed the data to be coded through three main headings/themes:

(1) Causes of intercultural conflict among Sunway University student

(2) impact of intercultural conflict on individuals and their relationships

(3) conflict management styles

\subsection{Causes of intercultural conflict Questions}

1) how often do you face intercultural conflict with your peers in Sunway University

Table 1: how often do Sunway Students experience intercultural conflict

\begin{tabular}{cc}
\hline Participants & How often \\
\hline Participant 1 & Not often \\
Participant 2 & Often \\
Participant 3 & Not often \\
Participant 4 & A lot often \\
Participant 5 & often \\
Participant 6 & Not often \\
\hline
\end{tabular}

Table 1 shows how often Sunway university students face intercultural conflict in campus with their peers. participant 1,3 and 6 responded that they seldom often go through intercultural conflict with their peers in campus while participant 2 and 5 responded that they often face intercultural conflict with their peers in campus. The remaining participant 4 responded that they faced a quite lot of intercultural conflict with their peers in Sunway University.

Question 2: In most intercultural conflict that you have gone through, explain the common causes of the conflict

Table 2: Result of causes of intercultural conflict.

\begin{tabular}{ll}
\hline Participants & \multicolumn{1}{c}{ Causes of Intercultural conflict } \\
\hline Participant 1 & Misinterpretation, Misunderstanding \\
Participant 2 & Food, Aggression, \\
Participant 3 & Misunderstanding, difference in opinions, different personalities \\
Participant 4 & Misunderstanding \\
Participant 5 & Language, difference in background \\
Participant 6 & Not meeting other party's requirement, miscommunication, difference in \\
& Background \\
\hline
\end{tabular}


Table 1 highlights the responses from the participants on what they consider the causes of intercultural conflict among youths in Sunway university. It was visible from the responses gathered by the interviewees that misunderstanding, differences in personality, background, language as well as opinions are common causes of intercultural conflict among Sunway students. The interview noted that a great number of the targeted participants considered misunderstanding as one of major cause of intercultural conflict.

"I think it may be having many friends there is bound to be misunderstanding, different opinions, arguments some people have like a really huge ego, Different personalities I will say all of those other causes."

"Typically, it happens because of one- or two-people's mistakes and eventually everybody world in conflict one way or another, so it's someone else's mistake or my own mistake, or the person who started the conflict made a mistake first. from my perspective intercultural conflict happens due to a mistake or misunderstanding. I think misunderstanding is the more pressing issue hence biggest cause of intercultural conflict."

The response given by the participants is consistent with the theoretical assertation made by Poyrazli, Kavanaugh, Baker, \& Al-Timimi, (2004). Some participants on the other had a different view that food and aggression was the cause of many of his intercultural conflict with his peers on campus. participants commented that:

"The common causes about the conflicts I've gone through is from little stuff, like the way we think, and even something as little as food. When I'm friends with people from middle east I find them a little bit more aggressive, they become emotional and tend to fight. I consider aggression part of the causes why i face intercultural conflict with some of my friends, because I'm calmer and when they come in aggressively our opinions just clash.”

"It's usually language, even though my number one language is Malay but in campus, because we are in a university setting and the English is the best, so I speak in English, but a lot of my classmates are from Chinese school backgrounds. It's not really a Chinese thing but it's a background thing. I see that they like to talk Chinese more even if $i$ am in front of them, but the ones that are from international school speaks English so it's easy to communicate with them."

A considerable number of the respondents commented that, while they get into intercultural conflicts, often time they are not the cause of the conflict. These results can be seen from table 2 listed below:

Table 3: Result of who causes the intercultural conflict

\begin{tabular}{cc}
\hline Participants & $\begin{array}{c}\text { Who caused the conflict? } \\
\text { (ME/ the other party/ depends/ both } \\
\text { parties) }\end{array}$ \\
\hline Participant 1 & Both parties \\
Participant 2 & Depends \\
Participant 3 & Both parties \\
Participant 4 & The other party \\
Participant 5 & depends \\
Participant 6 & The other party \\
\hline
\end{tabular}

Table 2 highlights responses from the interviews stating the parties that causes intercultural conflict. The respondents were asked to identify who or what situation they thought intercultural conflict emerged from. participant 1 and 3 responded that the conflict emerged from both parties while, participants 2 and 4 responded that the cause of the conflict depends on the situation in which the conflict took place and not necessarily the party. Some participants responded that intercultural conflict arose from the other party and not them. 
They noted that:

"In most cases it was the other person that caused the conflict but to be honest I've had cases where I was also the cause due to miscommunication and misinterpretation of what the person may have said or how the person may have acted."

"typically I'm not the one Who caused the conflict, because typically I like to keep to myself or when I'm doing this work or talking to them I don't try to confront people unless they are really making trouble and they need to be addressed which happens once or twice, usually it's the other way there's always one or two people one more confrontational and it caused those conflicts."

Other students had different views on who they taught instigated the conflict. Some participants felt that the conflict arose from both side and there was no need to put the blame on who could've been responsible.

"Most probably I think it depends on the situation, sometimes it's me sometimes it's them. The Indonesian culture is different from the Malaysian culture. The culture in Malaysia is a little bit more open than Indonesia. Sometimes i find Malaysian students too open and I'm the opposite. I find that Malaysian can talk about everything even private things.

"It's not really a person kind of thing, it could be but honestly i just feel it's because of language. It's not really because of the personality of the person but more about language, because each of us have different languages, so when they communicate their preferences is different from mine, and it's very hard therefore it causes issues between us."

When it came to whether the viewed intercultural conflict as a natural occurrence or the otherwise, all participants were of the view that it is indeed a natural occurrence as they cannot avoid it and it's bound to happen one way or another.

"It's a natural occurrence because first of all, there are seven continents in the world and approximately more than 7 billion people There is a lot of differences a lot of cultures a lot of values things just aren't the same all over the world it would be very close minded for someone to think so."

"I think it's a natural occurrence because i think culture is already in our heart. We cannot change our culture and we cannot avoid intercultural conflict because some things that are normal in our cultures can be a taboo in other people's culture so there's no way, we can avoid it, so it's natural, the only thing we can do is to learn about other people's culture in order not to offend them."

"I mean it's common, it is a natural occurrence. I think it's natural because something like misunderstanding just happens, we don't use it to happen sometimes it's like on purpose like somebody attacking somebody's religion but mostly is based on misunderstanding.

Intercultural conflict is without a doubt a natural thing, when different cultures interact the way they look at things and the way they think about things, the way they are brought up, everything will clash, very tiny details could cause conflict. I think its natural and it's not a bad thing at all."

"I feel that its natural because me myself $i$ don't feel that $i$ did nothing wrong and the other person too feels that they didn't do something wrong, so i guess it's natural that things like this will happen because we are not perfect but i guess we learn. I think that it's fine we have intercultural conflict." 


\subsection{Impact of intercultural conflict on individuals and their relationships}

It is without a doubt that intercultural conflict has its positive or negative impacts depending on the individual it can impact them both negatively and positively. Participants were asked on what they think intercultural conflict mean to them and how much does it impact their interpersonal relationship with peers in campus and would they consider it as something negative or positive towards them.

Some participants highlighted that encountering intercultural conflict with their peers in campus gave them the opportunity to learn from those experiences in order to better relate with their peers in campus. When asked on whether they considered intercultural conflict as something negative or positive towards them, they both stated that they saw it as something positive. Participant 1 expressed that intercultural conflict helped her understand how relate better with people from different cultures and backgrounds, while others stated that intercultural conflict did not affect the relationship he has with his peers instead, having to go through these conflicts helped him to become more mature, and has taught him how to respect other people's culture for them to reciprocate back.

Similar responses were gathered from participants on what they thought interculturalconflict meant to them and how it affected and impacted their interpersonal relationships. The respondents expressed that intercultural conflict affected the relationship they once had with the other party, it changed the way they saw the person regardless or being a friend or a stranger. Some participant expressed that they viewed intercultural conflict, as something negative towards her as they believed there's not any type of positive conflicts, as the results always tend to go towards the negative side. Others also stated that intercultural conflict has made them become less interested to remain friends with the other party. They were quoted saying that:

"I feel that I have become more less interested to become friend with them, it's not that I am not friends, it's just that the eagerness to maintain a conversation is not there anymore."

Some also expressed that they viewed intercultural conflict as something negative towards them as they believed it creates a barrier between them and their friends. A Participant highlighted that intercultural conflict affects her relationship with her peers in campus.

She expressed that:

"Yes, the more I face it the more I start doubting people so yes it would be affected."

She further elaborated that she viewed intercultural conflict as something negative towards her although it has it good and bad. She expanded this belief by quoting:

"Intercultural conflict can be both ways, it can be positive because you are learning something from it, but it can be negative because it can bring you down as a person. It can bring you down in a sense where you start doubting your work, the things that you say to the opposite person. It can go both ways but $i$ will say it's more on the negative side."

Some Participant however had a different response compared to the other participants. They expressed that he has been on both hand on the line whereby intercultural conflict affected their relationships both positively and negatively. They explained that in situations where it was positive, the kept the relationship going despite having conflicts with them. In the negative cases, they didn't want to keep contact as the relationships soured due to those conflict. They highlighted intercultural conflict as something positive towards them although they are not oblivious on the occasions whereby it can go wrong. they expressed that: 
"I think majority of cases it can be considered to be more towards the positive side because conflict happens due to clashes in opinions and resolving this conflict is a good thing because eventually both parties will benefit from it, at the same time there are some people who refuse to understand where you're coming from or where others are coming from and as such things happens that unfortunately relationships end or people start getting into trouble because of it. I will say mostly positive but there are quite a number of occasions where it can go wrong."

\subsection{Discussion}

In terms of our first research question that looks at the difference causes of intercultural conflict among Sunway university students, the results showed that the most common cause of intercultural conflict was misunderstanding. A lot of the participants placed misunderstanding at the forefront when it comes to what generates the conflict they experience with other parties. Other responses such as miscommunication, misinterpretation and aggression were mentioned, although not highly regarded as misunderstanding.

When it comes to our second research question, which looks at the different conflict management styles Sunway university use to overcome conflict, the respondents were asked their management styles based on four different categories; gender, religion, race, culture. Questions were asked in this manner to obtain difference perspective and styles that students used when confronted with different issues and the responses can be assessed from Table 4.

\subsection{Conflict management styles}

Table 4: Results of conflict management styles used by Sunway University

\begin{tabular}{|c|c|c|c|c|}
\hline Participants & Gender & Religion & Race & Culture \\
\hline Participant 1 & $\begin{array}{l}\text { Compromising } \\
\text { style }\end{array}$ & $\begin{array}{l}\text { Integrating } \\
\text { style }\end{array}$ & Avoiding style & $\begin{array}{l}\text { Integrating } \\
\text { style }\end{array}$ \\
\hline Participant 2 & Avoiding style & Not an issue & Obliging style & Integrating style \\
\hline Partic & $\begin{array}{l}\text { Integrating } \\
\text { style }\end{array}$ & $\begin{array}{c}\text { Avoiding/ } \\
\text { integrating style }\end{array}$ & Avoiding style & Not an issue \\
\hline Participant 4 & Not an issue & Not an issue & Avoiding style & $\begin{array}{l}\text { Compromising } \\
\text { style }\end{array}$ \\
\hline Participant 5 & Avoiding style & Not an issue & Avoiding style & $\begin{array}{l}\text { Compromising } \\
\text { style }\end{array}$ \\
\hline Participant 6 & $\begin{array}{l}\text { Compromising } \\
\text { style }\end{array}$ & Not an issue & $\begin{array}{l}\text { Compromising } \\
\text { style }\end{array}$ & $\begin{array}{l}\text { Integrating } \\
\text { style }\end{array}$ \\
\hline
\end{tabular}

CONCERN FOR SELF

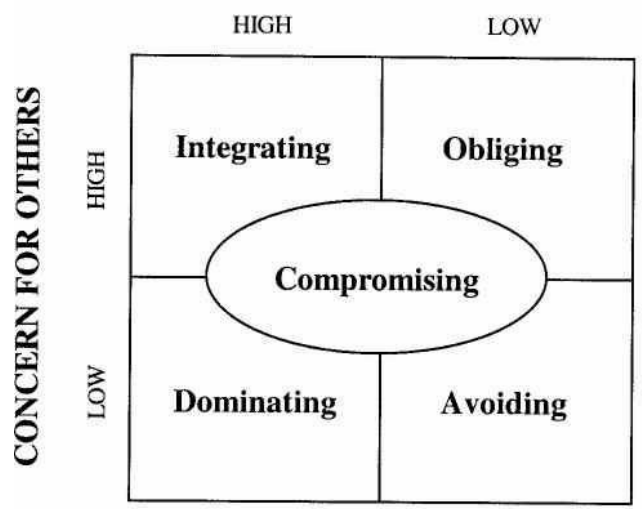

Figure 1: conflict management style Source: M. Afzalur Rahim, (1999) 


\subsubsection{Avoiding style}

In considering the pliability of various conflict management styles, the avoiding style (low concern for self and others) scored the greatest point which suggested that, it was the most commonly adapted style according to the responses given by the participants. Avoiding style was used the most when it came to overcoming issues involving culture. Majority of the participants considered avoiding style the go-to style of dealing with racial issues as it made them uncomfortable due to the recent happenings in the world is relation to racial issues. When it came to gender, two participants who found it the best way to overcome their conflict also used avoiding style. in response to some of the questions asked in relation to gender and race, they were of the assertation that conflicts can be avoided when certain problems are ignored.

A male participant noted that:

"Because I'm a quiet person right I usually just stay silent because $i$ believe silent is golden so it's better I just keep quiet, if they want to be angry with me or hit me, I don't mind because I don't want the conflict to be more complicated. I just avoid them."

A female participant also noted that:

"Usually i just avoid them because I don't really talk to boys because in my class, I'm the only Malay, so I'm more comfortable talking to people who are approachable so most of them are not approachable as seen by me, so I just avoid them."

\subsubsection{Integrating style}

There were some participants who also strongly advocated for the integrating style as means of managing their cultural conflicts compared with religion, race and gender which only had one response each for this part. This was because this style expressed high concern for both self and others, participants that chose this style were of the view that cultural conflict has a lot to do with respect. They believed that if they respect the culture of other peers in campus, they will reciprocate and hence held high esteem when it came to cultural conflict, advocating their reason for choosing the compromising style as a way of managing intercultural conflict, some of the responded shared their view of this for example,

An international participant noted that:

"For culture $i$ think it depends, like i said earlier, every culture is different, as long as i respect their culture they'll respect mine, so I have not encountered much conflict because of culture because culture is something we cannot separate. I believe that the more we understand about each other's culture the more we connect well to them."

Another participant also expressed that:

"I believe managing intercultural conflict has to do with a respecting Other people's values and not just yours."

\subsubsection{Compromising style}

From the responses provided by the participants, compromising style scored as well in terms of its flexibility in managing cultural, racial and gender issues. This was because most responded felt that this style was easier to implement especially when dealing with people from different cultures that necessary don't want to integrate and find the common ground. Some participant felt that compromising was a better choice especially when dealing with peers that form the majority in that setting. This clearly demonstrates that it's not easy managing an intercultural conflict especially when you're of the minority. 
The male participant noted that:

"I don't really have problems with students from different culture except like i say before the Malays, because of our cultural differences but other than that $i$ usually change my style to accommodate them, because most of the time when $i$ have conflict with them they are part of the larger group, as such $i$ have to change my style and more or less have to surrender to their demands because they are the majority, but at the same time $i$ don't fully surrender because I still hold strongly to my beliefs that what $i$ did is right. I try to be peaceful but firm."

\subsubsection{Obliging style}

Respondents when dealing with racial issue considered the obliging style efficient. The participant was of the assertation that when arguments don't go as planned with people of other races he has to give in and let them have their way even though that's not what he truly wants. The participant believed putting other people first in this situation can bring in more harmony than trying to prove his point. In the interview he noted that:

"I just keep quiet because $i$ don't understand anything and there's nothing $i$ can do. Sometimes $i$ try to ask what they are talking and sometimes they answer me other times they just ignore me so i have to let it go."

\subsubsection{Dominating style}

The dominating style was the least used of all the style as no participant thought it was needed to solve their intercultural conflicts. They all felt other styles could be of better use, as here the party seeks to worry of his/her own interest neglecting the interested of others, and hence it's low marking as a managing style. The aim of this research was to find the common causes of intercultural conflict and its management styles among Sunway university students. Past researchers found out that intercultural conflict can take place when both parties fail to meet up to each other's expectations which are usually causes by misunderstanding and difference in opinion (Ruble and Zhang, 2013; Wei, Tsai, Chao, Du, and Lin, 2012). The results gather here through this research further contributes to the idea, that though these scenarios and happen all over the world and experienced by different people across the globe, they all have similar reasons. In relation to the conflict management styles the responses varied compared to other researchers. Past researchers such as Ellen Toku that found out in their study that the most preferred style of managing conflict among students in basic school was the integrating style followed by the compromising obliging, avoiding and dominating style, whereas this research shows that Sunway university student preferred the avoiding style followed by the integrating, compromising, obliging and dominating style. This proves that although everyone going through similar situation, how he or she chose to handle it solely depends on hem and what they are comfortable with. its steady proves the fact that everyone is different, and people must try to find appropriate ways to deal with each other in order to solve conflict.

\section{CONCLUSION}

The results of the qualitative study were successful at answering the two research questions proposed by the researcher in this research. In terms of our first research questions which looks at the different causes of intercultural conflict among Sunway students, the research concludes that misunderstanding, miscommunication misinterpretation, food, aggression, different background, different personality, language were the causes of intercultural conflict among Sunway university students. Above all the causes mentioned misunderstanding was the most popular response given by participants compared to others causes.

In terms of our second research question, which looks at the different management style used by Sunway university students to overcome conflict, the avoiding style scored the most as many 
participants could relate to it in different scenarios. The least style used by participants to overcome crisis was the dominating style as they thought it wasn't needed. Ultimately these research findings add to existing works on intercultural conflict and its various causes and management styles used by individuals to manage conflicts in terms of gender, race religion and culture.

\subsection{Limitations}

The researcher acknowledges certain limitations associated with this study. The research conducted had some participants that were not proactive, hence some questions were answered briefly. This also reflected in the participant's level, as some participants were more active than others in the way they responded therefore the participant's level was not equal. The research also had lack of literature within the scope of study as there were authors that repeatedly cited the same thing therefore, no new literature could've been added the ones already mentioned.

\subsection{Recommendations}

Further research on intercultural conflict and its management style can broaden the scope by using a quantitative method of study that will enable a lot of students to give their views rather than going indepth to increase the generalizability of results. Further research may also consider doing a comparison study between international students vs. local students or male vs. female to determine who are better at managing intercultural conflict.

\section{REFERENCE}

Austin, Z. and Sutton, J. (2015). Qualitative Research: Data Collection, Analysis, and Management. [online] PubMed Central (PMC). Available at: https://www.ncbi.nlm.nih.gov/pmc/articles/PMC4485510/ [Accessed 20 Nov. 2018].

Bao, Y., Zhu, F., Hu, Y., \& Cui, N. (2016). The Research of Interpersonal Conflict and Solution Strategies. Psychology, 07(04), 541-545. http://dx.doi.org/10.4236/psych.2016.74055

Bazezew, A., \& Neka, M. (2017). Interpersonal Conflicts and Styles of Managing Conflicts among Students at Bahir Dar University, Ethiopia. Journal Of Student Affairs In Africa, 5(1). http://dx.doi.org/10.24085/jsaa.v5i1.2480

Braun, V. and Clarke, V. (2006) Using thematic analysis in psychology. Qualitative Research in Psychology 3 (2): 93.

Corbin, J., \& Strauss, A. (1990). Grounded theory research: Procedures, canons, and evaluative criteria. Qualitative Sociology, 13(1), 3-21. http://dx.doi.org/10.1007/bf00988593

Deutsch, M. (2003). Cooperation and Conflict: A personal Perspective on The history of the Social Psychological Study of Conflict Resolution. In M. A. West, D. Tjosvold \& K. G. Smith (Eds.), International handbook of organizational teamwork and cooperative working (pp. 9-44). West Sussex, England: John Wiley \& Sons.

Dudovskiy, J. (2012). Purposive sampling. Research Methodology. Retrieved 26 October 2016, from http://research-methodology.net/sampling-in-primary-datacollection/purposive-sampling/

Gordon, J. (2003). The Pfeiffer book of successful conflict management tools. San Francisco: John Wiley \& Sons, Inc.

Hamlin, A., \& Jennings, C. (2004). Group formation and political conflict: Instrumental and expressive approaches. Public Choice, 118(3/4), 413-435

Hammer, M. R. (). Additional cross-cultural validity testing of the Intercultural Development Inventory. International Journal of Intercultural Relations.

Hammer, M. R. (). The Intercultural Development Inventory manual. Berlin, MD: IDI.

Hammer, M. R. (a). The Intercultural Development Inventory: An approach for assessing and building intercultural competence. In M. A. Moodian (Ed.), Contemporary leadership and intercultural competence: Exploring the cross-cultural dynamics within organizations. Thousand Oaks, CA: Sage 
Lee, K., \& Chen, S. (2015). Brief Report: Interpersonal Conflicts between Chinese and Taiwanese International Students. Journal of Psychology and Behavioral Science, 3(2). http://dx.doi.org/10.15640/jpbs.v3n2a7

Leung, K. (1987). Some determinants of reactions to procedural models for conflict resolution: A crossnational study. Journal of Personality and Social Psychology, 53, 898-908.

Leung, K. (1988). Some determinants of conflict avoidance. Journal of Cross-Cultural Psychology, 19,125-136.

Leung, K., \& Iwawaki, S. (1988). Cultural collectivism and distributive behavior. Journal of Crosscultural Psychology, 19, 35-49

Marcus, E. C. (2014). Change and conflict: Motivation, resistance, and commitment. In M. Deutsch, P. T. Coleman, \& E. C. Marcus (Eds.), The handbook of conflict resolution: Theory and practice (3rd ed., pp. 513-532). San Francisco, CA: Jossey-Bass

Martin, J. N. \& Nakayama, T. K. (2013). Intercultural communication in contexts. (6 $6^{\text {th }}$ ed.). Singapore: McGraw-hill

Otieno Ayoma, E. (2015). Influence of interpersonal conflicts on the students' academic performance in Kenya.

Rahim, M.A. \& Bonoma, V.T. (1979). Managing organizational conflict: a model for diagnosis and intervention, Psychological Reports, Vol. 44, pp. 1323-44.

Rahim, M.A. (1985). A Strategy for Managing Conflict in Complex Organizations. Human relation, 38:81

Rahim, M.A. (1990). Theory and research in conflict management. New York: An Imprint of Greenwood Publishing Group, Inc.

Roloff, M. E., \& Soule, K. P. (2002). Interpersonal Conflict: A Review. In M. L. Knapp \& J.A. Daly (Eds.), Handbook of interpersonal communication (3rd ed., pp. 475 28). Thousand Oaks, CA: Sage.

Ruble, R.A., \& Zhang, Y. (2013). Stereotypes of Chinese international students held by Americans. International Journal of Intercultural Relations, 37(2), 202-211. Doi: 10.1016/j.ijintrel.2012.12.004

Shupe, E. I. (2007). Clashing cultures: A model of international student conflict. Journal Of CrossCultural Psychology, 38(6), 750-771. Doi: 10.1177/0022022107308996

Ting-Toomey, S. (2006). Managing intercultural conflict effectively. In L. A. Samovar, R. E.Porter \& E. R. McDaniel (Eds.), Intercultural communication: A reader (pp. 366-377). Belmont, CA: Wadsworth.

Toku, E. (2014). Conflict management practices in selected basic schools in the Ashanti region. [online] Ir.knust.edu.gh. Available at: http://ir.knust.edu.gh/bitstream/123456789/7633/1/FINAL\%20 PROJECT\%20MBA.pdf (Accessed 18 Oct. 2018).

Webb, C. (2017). Moving on or digging deeper: Regulatory mode and interpersonal conflict res.: Search All. Retrieved from http://eds.b.ebscohost.com/eds/pdfviewer/pdfviewer?vid=1\&sid $0 \mathrm{~b} 25 \mathrm{~cd} 60$ d834-4dac-a43b-84a444960ccb\%40pdc-v-sessmgr01

What is Conflict? (2018). Retrieved from https://sielearning.tafensw.edu.au/toolboxes/toolbox316/rm/rm_c19.html 
Idealogy Journal

Volume 5 Issue 22020

媇" IDEALOGY

JOURNAL 